Review

\title{
Repressing CD147 is a novel therapeutic strategy for malignant melanoma
}

\author{
Xing Hu${ }^{1,2}$, Juan Su${ }^{1,2}$,Youyou Zhou ${ }^{2}$, Xiaoyun Xie ${ }^{1,2}$, Cong Peng ${ }^{1,2}$, Zhimin Yuan ${ }^{3}$ \\ and Xiang Chen ${ }^{1,2}$ \\ ${ }^{1}$ Department of Dermatology, Xiangya Hospital, Central South University, Changsha, China \\ ${ }^{2}$ Hunan Key Laboratory of Skin Cancer and Psoriasis, Xiangya Hospital, Central South University, Changsha, China \\ ${ }^{3}$ Department of Genetics and Complex Diseases, Harvard T.H Chan School of Public Health, Boston, MA, USA \\ Correspondence to: Juan Su, email: sujuanderm@csu.edu.cn
}

Xiang Chen, email: chenxiangck@126.com

Keywords: cyclophilin A, CD147, melanoma, cell proliferation, MMPs

Received: December 21,2016 Accepted: January 22, $2017 \quad$ Published: February 25, 2017

Copyright: Hu et al. This is an open-access article distributed under the terms of the Creative Commons Attribution License (CC-BY), which permits unrestricted use, distribution, and reproduction in any medium, provided the original author and source are credited.

\section{ABSTRACT}

CD147/basigin, a transmembrane protein, is a member of the immunoglobulin super family. Accumulating evidence has revealed the role of CD147 in the development and progression of various cancers, including malignant melanoma (MM). MM is a malignancy of pigment-producing cells that causes the greatest number of skin cancer-related deaths worldwide. CD147 is overexpressed in MM and plays an important role in cell viability, apoptosis, proliferation, invasion, and metastasis, probably by mediating vascular endothelial growth factor (VEGF) production, glycolysis, and multi-drug resistance (MDR). As a matrix metalloproteinase (MMP) inducer, CD147 could also promote surrounding fibroblasts to secrete abundant MMPs to further stimulate tumor cell invasion. Targeting CD147 has been shown to suppress $M M$ in vitro and in vivo, highlighting the therapeutic potential of CD147 silencing in MM treatment. In this review article, we discuss CD147 and its biological roles, regulatory mechanisms, and potential application as a molecular target for MM.

\section{INTRODUCTION}

It is estimated that the annual increase in the incidence rate of melanoma has been approximately $3-7 \%$ per year worldwide for Caucasians which has the highest incidence[1]; over $90 \%$ of U.S. patients with cutaneous Malignant Melanoma (MM) are non-Hispanic whites. However, Cockburn et al. reported that the rate of MM in Hispanic whites is rising [2,3], and the melanoma occurrence rates have doubled in all socioeconomic status (SES) groups over the last decade [3]. A "good clinical eye" is an "ABCD" rules method-based approach that can be used to reduce melanoma mortality $[4,5]$. Tumor invasiveness, distant metastasis, recurrence, and multidrug resistance (MDR) make MM a leader of fatalities despite a plethora of treatment options, including surgery, chemotherapy, and radiotherapy [6-8]. Therefore, it is necessary to explore effective methods for improving outcomes.

The mechanisms of malignant melanoma are complicated, but include sunlight exposure and heredity
$[9,10]$. The pathogenesis of UV light exposure is largely unknown, but it directly leads to DNA mutation and accelerates malignant change through overexpressed growth factors like stem cell factor and fibroblast growth factor. MM's resistance to apoptosis reveals that the cancer has a genetic component [11-13]. Recent studies by our group have shown that CD147 plays a pivotal role in the pathogenesis and progression of $\mathrm{MM}$ and other diseases [14-23]. Moreover, CD147 has the potential to serve as a novel therapeutic target for MM with multiple drug resistance. In the last decade, we reported that downregulation and gene knockdown of CD147 could suppress MM's proliferation, invasiveness, and metastasis. This approach could also stimulate the production of matrix metalloproteases (MMPs), and change the glycolysis level and interaction with calcium-modulating cyclophilin ligand through a dynamic pathway [24-29]. Recently, our team found that CD147 is expressed in the mitochondria and interacts with NDUFS6 to influence complex I viability of MM cell lines. This process may involve the regulation of oxidative phosphorylation (OXPHOS); as a result, CD147 moves to the cytoplasm from the membrane 
Table 1: Major clinical trials or treatments for CD147-based therapy in MM

\begin{tabular}{|c|c|c|c|}
\hline Disease & Description & Year & References \\
\hline Sepsis-induced acute renal failure & $\begin{array}{l}\text { Inhibition of the cyclophilin receptor CD147 attenuates } \\
\text { sepsis-induced acute renal failure }\end{array}$ & 2007 & Crit Care Med \\
\hline Oral squamous carcinoma & $\begin{array}{l}\text { Inhibition of CD147 and subsequent XIAP depletion } \\
\text { may have an anti-tumor effect through enhancing the } \\
\text { susceptibility of cancer cells to apoptosis }\end{array}$ & 2009 & Cancer Lett. \\
\hline Acute Myeloid Leukemia & $\begin{array}{l}\text { Co-expression of CD147 and vascular endothelial growth } \\
\text { factor may indicate a poor prognosis in acute myeloid } \\
\text { leukemia and may be a highly sensitive marker for } \\
\text { predicting the clinical outcome of patients }\end{array}$ & 2010 & Jpn J Clin Oncol \\
\hline Jurkat T-Lymphoma & $\begin{array}{l}\text { Inhibition of CD147 reduces proliferation, activation, } \\
\text { adhesion, and migration in human Jurkat T-Lymphoma cells }\end{array}$ & 2008 & Cancer Invest. \\
\hline Breast cancer & $\begin{array}{l}\text { CD147 mediates chemoresistance in breast cancer } \\
\text { via ABCG2 by affecting its cellular localization and } \\
\text { dimerization }\end{array}$ & 2013 & Cancer Lett. \\
\hline Breast cancer & $\begin{array}{l}\text { Thrombin-cleaved COOH-terminal osteopontin peptide } \\
\text { binds with Cyclophilin C to CD147, and contributes to in } \\
\text { vitro migration and invasion in Murine Breast Cancer }\end{array}$ & 2007 & Cancer Res. \\
\hline Malignant melanoma & $\begin{array}{l}\text { CD147-targeting siRNA inhibits cell-matrix adhesion of } \\
\text { human malignant melanoma cells by phosphorylating focal } \\
\text { adhesion kinase }\end{array}$ & 2012 & J Dermatol. \\
\hline Malignant melanoma & $\begin{array}{l}\text { CD147 is involved in the uncharacterized }[\mathrm{Ca} 2+] \mathrm{i} \text { signaling } \\
\text { pathway that may control melanoma invasion, and } \\
\text { metastasis }\end{array}$ & 2013 & Cancer Lett \\
\hline Malignant melanoma & $\begin{array}{l}\text { Inhibition of CD147 suppresses the proliferation, } \\
\text { invasiveness, and VEGF production of human malignant } \\
\text { melanoma cells by down-regulating glycolysis }\end{array}$ & 2009 & Cancer Lett \\
\hline Malignant melanoma & $\begin{array}{l}\text { Inhibition of CD147 suppresses the proliferation, } \\
\text { invasiveness, and metastatic activity of malignant melanoma }\end{array}$ & 2006 & Cancer Res \\
\hline Malignant melanoma & $\begin{array}{l}\text { Depletion of CD147 sensitizes human malignant melanoma } \\
\text { cells to hydrogen peroxide-induced oxidative stress }\end{array}$ & 2010 & J Dermatol Sci. \\
\hline Malignant melanoma & $\begin{array}{l}\text { CD147 is expressed on melanoma cell and induce cell } \\
\text { invasion by stimulating MMPs secretion by fibroblasts }\end{array}$ & 2002 & Int J Cancer. \\
\hline Psoriasis & $\begin{array}{l}\text { CD147 is highly expressed on peripheral blood neutrophils } \\
\text { from patients with psoriasis and induces neutrophil } \\
\text { chemotaxis }\end{array}$ & 2010 & J Dermatol. \\
\hline Psoriasis & $\begin{array}{l}\text { A miRNA-492 binding-site polymorphism in CD147 } \\
\text { confers risk to psoriasis in Central South Chinese population }\end{array}$ & 2011 & Hum Genet. \\
\hline
\end{tabular}

in MM cells [22]. We also reported that CD147 interacted with TRAF6 through ubiquitination to regulate MM`s invasion and metastasis [23]. Therefore, elucidating the underlying mechanisms of CD147-mediated MM metastasis is clinically significant for improving the treatment of MM. In this review, we summarize CD147's function in MM and the signaling pathways it activates, and discuss its potential role in MM treatment.

\section{BIOLOGY OF CD147}

\section{General information}

CD147, the symbol for the human Basigin (Bsg) gene, is a transmembrane glycoprotein with two immunoglobulin-like domains and is part of a family that includes embigin and neuroplastin. Several groups found
CD147 independently [30-32]: it is located at p13.3 on chromosome 19 [33]. CD147 was identified as a functional molecule involved in many cellular events, such as the inflammatory processes, as a receptor for cyclophilin A [31], and as a potential participant in HIV infection. Moreover, CD147 was found on the surface of tumor cells [34] and may trigger the production or release of MMPs in surrounding mesenchymal and tumor cells, thereby contributing to tumor invasion. The protein portion of CD147 is $28 \mathrm{kDa}$, but its high glycosylation increases its molecular weight to $43-66 \mathrm{kDa}$.

CD147 is an important cell-surface protein. There are three Asn glycosylation sites in the extracellular region[31, 34, 35]. The glycan portion differs according to the CD147 source. This glycosylation difference is responsible for various CD147 weights from different sources. CD147 has two Ig domains in the extracellular region. The more C-terminally located Ig-domain has an 
interesting characteristic; it has homology to both the V domain and the $\beta$-chain of the major histocompatibility complex class II, which has the $\mathrm{C}$ domain. The $\mathrm{V}$ domain and $\mathrm{C}$ domain in $\mathrm{IgG}$ are only remotely related.

\section{The biological function of CD147 in cancer}

CD147 was found on the surface of tumor cells and promoted the production of MMPs in neighboring mesenchymal cells, leading to enhanced tumor invasion. CD147 is frequently overexpressed in human cancers, and significantly contributes to malignant phenotypes. Up-regulation of CD147 also has been noted in glioma, laryngeal squamous cell, ovarian, renal cell and skin carcinoma[36-39]. Further, CD147 enhances the invasion and survival of cancer cells in various pathways. Among these, the induction of MMPs [28, 34, 40] and vascular endothelial growth factor (VEGF) [40-42] is important. The former enhances tumor invasion and metastasis, while the latter leads to tumor angiogenesis. Cell surface expression of MCTs is required for tumor cell energy metabolism and contributes to their growth and invasion. Activities related to tumor cell survival include suppression of anoikis [43] and increased drug resistance. Furthermore, CD147 promotes hyaluronan synthesis [44], upregulates the Wnt/b-catenin signaling pathway [45], promotes the epithelial-mesenchymal transition [46], and receives a signal of an osteopontin peptide, together with cyclophilin C [47].

\section{The relationship between cyclophilin $A$ and CD147}

Cyclophilin A (CypA) is the host receptor for the immunosuppressive drug cyclosporin A. It is secreted from cells in response to an inflammatory reaction. CypA interacts with its cellular receptor CD147 to exert multiple functions in chemotaxis and cell signaling cascades [4850]. These correlations of CypA with tumor pathogenesis have been extensively studied [51, 52]. Campa et al. showed that CypA is the most dominantly expressed protein in non-small cell lung carcinoma [53], while Li et al. demonstrated that CypA plays an important role in pancreatic cancer growth through its interaction with CD147 [54]. CypA is a secreted growth factor induced by oxidative stress, and stimulates the ERK $1 / 2$ pathway and cell proliferation in vascular smooth muscle cells (VSMCs) $[55,56]$. The cytosolic concentration of CypA in T-cell acute lymphocytic leukemia and in mucosal cells from colonic tumors was higher than that in the normal cells. In addition, secreted CypA is chemoattractive to neutrophils, eosinophils, and T cells. Moreover, CD147 has been proposed as a receptor for cyclophilin A [57]. CD147 binds to cyclophilin A and transmits a signal to trigger chemotaxis, and Bsg is involved in signaling of a related protein. The involvement of CD147 in inflammation through binding with cyclophilin $\mathrm{A}$ is consistent with previous findings: CD147 becomes expressed in activated lymphocytes, CD147 is upregulated upon collagen-induced arthritis [58], and CD147-deficient lymphocytes exhibit an altered reaction upon mixed lymphocyte reaction.

\section{THE ROLE OF CD147 IN MALIGNANT MELANOMA}

\section{CD147 regulates cell proliferation and apoptosis of $\mathrm{MM}$ cells}

It has been well established that CD147 plays critical roles in mediating cell proliferation, apoptosis, and oxidative stress. Miho Hatanaka found melanoma cell growth was inhibited by CD147 silencing[59], Luo $\mathrm{Z}$ reported CD147 regulates mitochondrial apoptotic pathway in human malignant melanoma cells by interacting with NDUFS6[22]. And blocking CD147 induces cell death in cancer cells through impairment of glycolytic energy metabolism[60].Depletion of CD147 sensitizes human malignant melanoma cells to hydrogen peroxide-induced oxidative stress[16]. H2O2 has been shown to induce senescence in normal human skin fibroblasts, in our group we investigated the molecular influences and mechanisms of CD147 on H2O2-induced cellular senescence. We showed that under normal conditions, shRNA-mediated CD147 silencing could inhibit cell proliferation, induce premature senescence, and induce senescence-related cell cycle arrest. While under oxidative stress conditions induced by $\mathrm{H} 2 \mathrm{O} 2$, CD147 silencing exacerbated cellular senescence by increasing ROS accumulation and destroying the intrinsic antioxidant defenses. This process might be related to the klotho protein, a newly discovered anti-aging protein [16]. Since CD147 could promote the production and secretion of MMPs from skin fibroblasts, which is the major component of the microenvironment of MM [27], CD147 is potentially implicated in the development and progression of MM.

Accumulating evidence has gradually revealed the role of CD147 in the regulation of biological processes, including cellular viability, apoptosis, senescence, and oxidative stress, of MM cells. For instance, CD147 has been suggested to exert antioxidant activities. We investigated the effects of CD147 on proliferation, apoptosis, and the state of MM cells under $\mathrm{H}_{2} \mathrm{O}_{2}$-induced oxidative stress, and found that inhibition of CD147 increased cellular ROS and destroyed the intrinsic antioxidant defenses in A375 MM cells [26]. Our group showed that CD147 is not only located in cell membrane, but also in the cytoplasm by oxidative phosphorylation 
(OXPHOS) possibility [22]. This suggests that CD147 has a suppressive effect on $\mathrm{H}_{2} \mathrm{O}_{2}$-induced oxidative damage, and therefore protects against MM cell apoptosis.

\section{CD147 regulates angiogenesis of MM cells}

Angiogenesis plays a crucial role in the invasion and metastasis of malignant tumors [61], and CD147 has been reported to induce angiogenesis in pathological processes, including cancers [62-64]. Hatanaka M found CD147 regulates the angiogenesis by decreasing VEGF expression in vivo and reducing blood vessel formation[65]. Our group has demonstrated that the co-expression of CD147 and VEGF might indicate a poor prognosis in acute myeloid leukemia and may be a highly sensitive predictor of clinical outcome [66]. Furthermore, CD147 was found to participate in the regulation of angiogenesis in $\mathrm{MM}$. Su et al. showed that CD147 silencing could not only suppress MM cell proliferation and invasion, but also inhibited the production of VEGF in MM cells via downregulation of monocarboxylate transporters (MCT) 1 and MCT4. These transporters mediate lactate transport, suggesting that CD147 may promote tumor cell glycolysis and progression of MM through interacting with MCT1 and MCT4 [25]. We also demonstrated that siRNA-mediated CD147 silencing inhibited the expression of VEGF in MM cells and decreased endothelial cell migration, which is closely related to the invasion and metastasis of MM [29].
More importantly, we established a nude mouse xenograft model of MM and showed that downregulation of CD147 could suppress the tumor's size and microvessel density [29].

\section{CD147 regulates cancer invasion and metastasis in $\mathrm{MM}$}

Voigt $\mathrm{H}$ found CD147 impacts metastasis formation[65]. And blocking CD147 could inhibit the invasiveness, and metastatic activity of malignant melanoma[29]. In our group we recently showed that the endoplasmic reticulum (ER) -associated protein calciummodulating cyclophilin ligand (CAML) is bound to CD147 in human A375 melanoma cells. CD147 silencing significantly decreased resting $[\mathrm{Ca} 2+] \mathrm{i}$ and the $[\mathrm{Ca} 2+]$ $\mathrm{i}$ increase induced by the sarco/endoplasmic reticulum Ca2+-ATPase (SERCA) inhibitor thapsigargin (TG), indicating that the interaction between CAML and CD147 regulates ER-dependent [Ca2+]i signaling. Upregulation of $[\mathrm{Ca} 2+] \mathrm{i}$ could induce the production of MMP-9 in A375 cells with the expression of CD147[24]. Thus, CD147 may participate in the ER-dependent $[\mathrm{Ca} 2+] \mathrm{i}$ signaling pathway, which may mediate MM invasion and metastasis.

Thus, CD147 may act as an oncogene in MM, and targeting CD147 could inhibit cancer cell viability, proliferation, and invasion, while inducing cell senescence and apoptosis in MM cells. The underlying molecular

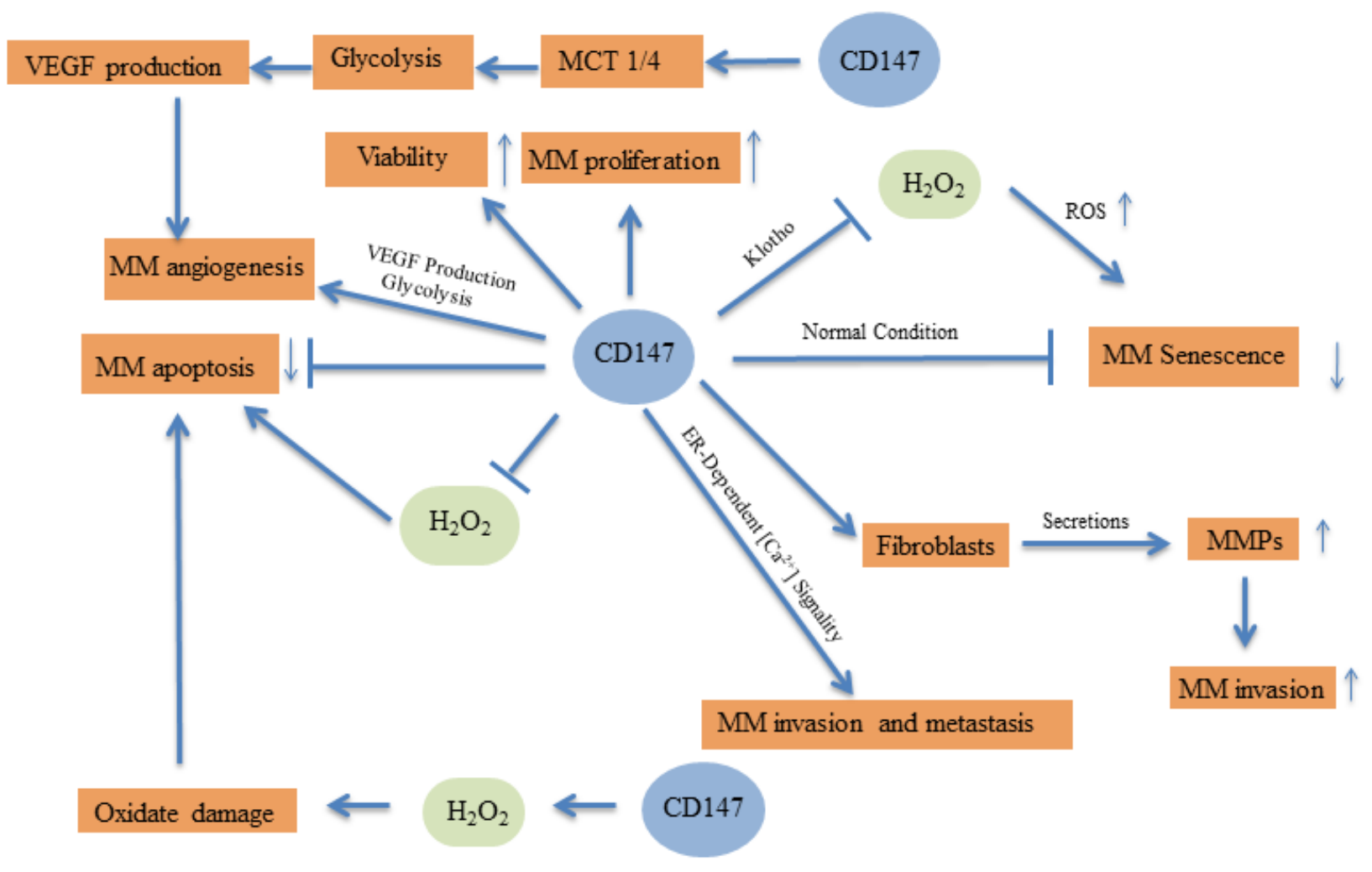

Figure 1: Molecular pathways of CD147 in malignant melanoma. 
mechanism responsible for this may be CD147's regulation of oxidative stress, glycolysis, and angiogenesis in either the MM cells or surrounding cells in the tumor microenvironment.

\section{THERAPEUTIC POTENTIAL}

Since CD147 plays a role in various diseases, it has recently been suggested as a promising target for the treatment of various diseases. For instance, liver sepsis could induce a universally altered profile of liver proteins, including increased cyclophilin. However, inhibition of CD147, the receptor of cyclophilin, could effectively attenuate sepsis-induced acute renal failure via inducing a significant reduction in serum cytokine production [67]. Thus, CD47-targeted therapy may help prevent sepsisinduced renal dysfunction. Furthermore, CD147 has been suggested to play a role in psoriasis. We showed that CD147 is highly expressed on peripheral blood smears and induces neutrophil chemotaxis [18]. We also found a miRNA-492 binding-site polymorphism in CD147. This conferred psoriasis risk upon the central south Chinese population, and suggested that this polymorphism might be associated with reduced psoriasis susceptibility, by affecting miRNA-492 binding [17]. Additionally, we suggested a role of CD147 in regulating ABCG2 transport of methotrexate in immune cells [15]. Therefore, strategies involving CD147 targeting could be considered for the clinical treatment of patients with psoriasis that is resistant to methotrexate. These findings emphasize the significance of CD147 in the development of psoriasis.

CD47 silencing also has applications in the treatment of malignant tumors. We found that CD147 had implications in the regulation of drug transport by mediating the expression and dimerization of ABCG2. This affected ABCG2's cellular localization and drug transporter function in breast cancer cells [14]. In addition, we found that siRNA-mediated CD147 inhibition could reduce proliferation, activation, adhesion, and migration in human Jurkat T-lymphoma cells [21]. We also investigated the effect and mechanisms of CD147 on the MDR phenotype of human oral squamous carcinoma cells (SCCs), and showed that the expression of CD147 and $\mathrm{X}$-linked inhibitor of apoptosis (XIAP) was upregulated in MDR-derivative SCCs compared with SCCs. We further revealed that inhibition of CD147 and subsequent XIAP depletion might have an anti-tumor effect through enhancing the susceptibility of cancer cells to 5-fluorouracil-induced apoptosis [20]. Since SCC and MM are both cutaneous carcinomas, targeting CD147 may also become a potential therapeutic strategy for the treatment of MM. Further, Chen and colleges reported that targeting CD147 could effectively suppress the size and microvessel density of tumors in a nude mouse xenograft model of MM. In addition, the in vivo metastatic potential of A375 cells transfected with CD147 siRNA was suppressed in a nude mouse model of pulmonary metastasis [29]. Accordingly, CD147 may become a potential therapeutic target for the treatment of MM, mainly because of its regulatory role in chemical resistance and tumor metastasis.

\section{CONCLUSIONS}

Despite recent progress on the diagnostic and therapeutic aspects of MM, the overall survival rate of patients with MM remains unchanged. Emerging evidence has gradually revealed the genomic information and interaction of signaling networks in MM cells, shedding new light on how to tailor an effective treatment. New emerging targets, such as CD147, can also be used to assess the prognosis and risk of recurrence in MM. However, further studies are needed to unravel the detailed mechanism of the CD147 pathway in MM and other cancers.

\section{ACKNOWLEDGMENTS}

This study was supported by grantsfrom the National Natural Science Foundation of China(NO. 81472882) and the National Science Fund for Distinguished Young Scholars(81225013), Natural Science Foundation of Hunan (11JJ5083), The Young Talents Support Plan of Hunan, P. R. China.

\section{CONFLICTS OF INTEREST}

There is no conflict of interest.

\section{REFERENCES}

1. Parkin DM, Bray F, Ferlay J, Pisani P. Estimating the world cancer burden: Globocan 2000. Int J Cancer. 2001; 94: 1536.

2. Cockburn MG, Zadnick J, Deapen D. Developing epidemic of melanoma in the Hispanic population of California. Cancer. 2006; 106: 1162-8. doi: 10.1002/cncr.21654.

3. Linos E, Swetter SM, Cockburn MG, Colditz GA, Clarke CA. Increasing burden of melanoma in the United States. J Invest Dermatol. 2009; 129: 1666-74. doi: 10.1038/ jid.2008.423.

4. Rigel DS, Russak J, Friedman R. The evolution of melanoma diagnosis: 25 years beyond the ABCDs. CA Cancer J Clin. 2010; 60: 301-16. doi: 10.3322/caac.20074.

5. Beddingfield FC, 3rd. The melanoma epidemic: res ipsa loquitur. Oncologist. 2003; 8: 459-65.

6. Balch CM, Gershenwald JE, Soong SJ, Thompson JF, Atkins MB, Byrd DR, Buzaid AC, Cochran AJ, Coit DG, Ding S, Eggermont AM, Flaherty KT, Gimotty PA, et al. Final version of 2009 AJCC melanoma staging and classification. J Clin Oncol. 2009; 27: 6199-206. doi: 
10.1200/JCO.2009.23.4799.

7. Thompson JF, Scolyer RA, Kefford RF. Cutaneous melanoma. Lancet. 2005; 365: 687-701. doi: 10.1016/ S0140-6736(05)17951-3.

8. Dummer R, Hauschild A, Pentheroudakis G. Cutaneous malignant melanoma: ESMO clinical recommendations for diagnosis, treatment and follow-up. Ann Oncol. 2009; 20 Suppl 4: 129-31. doi: 10.1093/annonc/mdp152.

9. Weinstock MA, Colditz GA, Willett WC, Stampfer MJ, Bronstein BR, Mihm MC, Jr., Speizer FE. Nonfamilial cutaneous melanoma incidence in women associated with sun exposure before 20 years of age. Pediatrics. 1989; 84: 199-204.

10. Ford D, Bliss JM, Swerdlow AJ, Armstrong BK, Franceschi S, Green A, Holly EA, Mack T, MacKie RM, Osterlind A, et al. Risk of cutaneous melanoma associated with a family history of the disease. The International Melanoma Analysis Group (IMAGE). Int J Cancer. 1995; 62: 377-81.

11. Vogelstein B, Kinzler KW. Cancer genes and the pathways they control. Nat Med. 2004; 10: 789-99. doi: 10.1038/ nm1087.

12. Soengas MS, Lowe SW. Apoptosis and melanoma chemoresistance. Oncogene. 2003; 22: 3138-51. doi: 10.1038/sj.onc.1206454.

13. Meyskens FL, Jr., Farmer PJ, Anton-Culver H. Etiologic pathogenesis of melanoma: a unifying hypothesis for the missing attributable risk. Clin Cancer Res. 2004; 10: 2581 3.

14. Zhou S, Liao L, Chen C, Zeng W, Liu S, Su J, Zhao S, Chen M, Kuang Y, Chen X, Li J. CD147 mediates chemoresistance in breast cancer via ABCG2 by affecting its cellular localization and dimerization. Cancer Lett. 2013; 337: 285-92. doi: 10.1016/j.canlet.2013.04.025.

15. Zhao S, Chen C, Liu S, Zeng W, Su J, Wu L, Luo Z, Zhou S, Li Q, Zhang J, Kuang Y, Chen X. CD147 promotes MTX resistance by immune cells through up-regulating ABCG2 expression and function. J Dermatol Sci. 2013; 70: 182-9. doi: 10.1016/j.jdermsci.2013.02.005.

16. Xie H, Liu L, Shi W, Xiao X, Tian L, Jian D, Chen X, Li J. Down regulation of CD147 boosts the premature senescence in human skin fibroblasts by destroying the redox balance and inhibiting klotho. J Dermatol Sci. 2011; 64: 243-5. doi: 10.1016/j.jdermsci.2011.09.010.

17. Wu LS, Li FF, Sun LD, Li D, Su J, Kuang YH, Chen G, Chen XP, Chen X. A miRNA-492 binding-site polymorphism in BSG (basigin) confers risk to psoriasis in central south Chinese population. Hum Genet. 2011; 130: 749-57. doi: 10.1007/s00439-011-1026-5.

18. Lu H, Kuang YH, Su J, Chang J, Wu LS, Kanekura T, Li D, Chen ML, Chen X. CD147 is highly expressed on peripheral blood neutrophils from patients with psoriasis and induces neutrophil chemotaxis. J Dermatol. 2010; 37: 1053-6. doi: 10.1111/j.1346-8138.2010.00935.x.
19. Kuang YH, Chen X, Su J, Wu LS, Liao LQ, Li D, Chen ZS, Kanekura T. RNA interference targeting the CD147 induces apoptosis of multi-drug resistant cancer cells related to XIAP depletion. Cancer Lett. 2009; 276: 189-95. doi: 10.1016/j.canlet.2008.11.010.

20. Kuang YH, Chen X, Su J, Wu LS, Li J, Chang J, Qiu Y, Chen ZS, Kanekura T. Proteome analysis of multidrug resistance of human oral squamous carcinoma cells using CD147 silencing. J Proteome Res. 2008; 7: 4784-91. doi: $10.1021 /$ pr800355b.

21. Chen X, Su J, Chang J, Kanekura T, Li J, Kuang YH, Peng S, Yang F, Lu H, Zhang JL. Inhibition of CD147 gene expression via RNA interference reduces tumor cell proliferation, activation, adhesion, and migration activity in the human Jurkat T-lymphoma cell line. Cancer Invest. 2008; 26: 689-97. doi: 10.1080/07357900701867892.

22. Luo Z, Zeng W, Tang W, Long T, Zhang J, Xie X, Kuang Y, Chen M, Su J, Chen X. CD147 interacts with NDUFS6 in regulating mitochondrial complex I activity and the mitochondrial apoptotic pathway in human malignant melanoma cells. Curr Mol Med. 2014; 14: 1252-64.

23. Luo Z, Zhang X, Zeng W, Su J, Yang K, Lu L, Lim CB, Tang W, Wu L, Zhao S, Jia X, Peng C, Chen X. TRAF6 regulates melanoma invasion and metastasis through ubiquitination of Basigin. Oncotarget. 2016; 7: 7179-92. doi: 10.18632/oncotarget.6886.

24. Long T, Su J, Tang W, Luo Z, Liu S, Liu Z, Zhou H, Qi M, Zeng W, Zhang J, Chen X. A novel interaction between calcium-modulating cyclophilin ligand and Basigin regulates calcium signaling and matrix metalloproteinase activities in human melanoma cells. Cancer Lett. 2013. doi: 10.1016/j.canlet.2013.07.019.

25. Su J, Chen X, Kanekura T. A CD147-targeting siRNA inhibits the proliferation, invasiveness, and VEGF production of human malignant melanoma cells by downregulating glycolysis. Cancer Lett. 2009; 273: 140-7. doi: 10.1016/j.canlet.2008.07.034.

26. Li J, Peng L, Wu L, Kuang Y, Su J, Yi M, Hu X, Li D, Xie H, Kanekura T, Chen X. Depletion of CD147 sensitizes human malignant melanoma cells to hydrogen peroxideinduced oxidative stress. J Dermatol Sci. 2010; 58: 204-10. doi: 10.1016/j.jdermsci.2010.03.022.

27. Kanekura T, Chen X, Kanzaki T. Basigin (CD147) is expressed on melanoma cells and induces tumor cell invasion by stimulating production of matrix metalloproteinases by fibroblasts. Int J Cancer. 2002; 99: 520-8. doi: 10.1002/ijc.10390.

28. Kanekura T, Chen X. CD147/basigin promotes progression of malignant melanoma and other cancers. J Dermatol Sci. 2010; 57: 149-54. doi: 10.1016/j.jdermsci.2009.12.008.

29. Chen X, Lin J, Kanekura T, Su J, Lin W, Xie H, Wu Y, Li J, Chen M, Chang J. A small interfering CD147targeting RNA inhibited the proliferation, invasiveness, and metastatic activity of malignant melanoma. Cancer 
Res. 2006; 66: 11323-30. doi: 10.1158/0008-5472.CAN06-1536.

30. Miyauchi T, Kanekura T, Yamaoka A, Ozawa M, Miyazawa $\mathrm{S}$, Muramatsu T. Basigin, a new, broadly distributed member of the immunoglobulin superfamily, has strong homology with both the immunoglobulin V domain and the beta-chain of major histocompatibility complex class II antigen. J Biochem. 1990; 107: 316-23.

31. Kanekura T, Miyauchi T, Tashiro M, Muramatsu T. Basigin, a new member of the immunoglobulin superfamily: genes in different mammalian species, glycosylation changes in the molecule from adult organs and possible variation in the N-terminal sequences. Cell Struct Funct. 1991; 16: 23-30.

32. Schlosshauer B, Herzog KH. Neurothelin: an inducible cell surface glycoprotein of blood-brain barrier-specific endothelial cells and distinct neurons. J Cell Biol. 1990; 110: 1261-74.

33. Kaname T, Miyauchi T, Kuwano A, Matsuda Y, Muramatsu T, Kajii T. Mapping basigin (BSG), a member of the immunoglobulin superfamily, to 19p13.3. Cytogenet Cell Genet. 1993; 64: 195-7.

34. Biswas C, Zhang Y, DeCastro R, Guo H, Nakamura T, Kataoka H, Nabeshima K. The human tumor cell-derived collagenase stimulatory factor (renamed EMMPRIN) is a member of the immunoglobulin superfamily. Cancer Res. 1995; 55: 434-9.

35. Watanabe A, Yoneda M, Ikeda F, Terao-Muto Y, Sato H, Kai C. CD147/EMMPRIN acts as a functional entry receptor for measles virus on epithelial cells. J Virol. 2010; 84: 4183-93. doi: 10.1128/JVI.02168-09.

36. Sameshima T, Nabeshima K, Toole BP, Yokogami K, Okada Y, Goya T, Koono M, Wakisaka S. Expression of emmprin (CD147), a cell surface inducer of matrix metalloproteinases, in normal human brain and gliomas. Int J Cancer. 2000; 88: 21-7.

37. Rosenthal EL, Shreenivas S, Peters GE, Grizzle WE, Desmond R, Gladson CL. Expression of extracellular matrix metalloprotease inducer in laryngeal squamous cell carcinoma. Laryngoscope. 2003; 113: 1406-10. doi: 10.1097/00005537-200308000-00027.

38. Liang YX, He HC, Han ZD, Bi XC, Dai QS, Ye YK, Qin WJ, Zeng GH, Zhu G, Xu CL, Zhong WD. CD147 and VEGF expression in advanced renal cell carcinoma and their prognostic value. Cancer Invest. 2009; 27: 788-93. doi: 10.1080/07357900802709167.

39. Chen X, Kanekura T, Kanzaki T. Expression of Basigin in human fetal, infantile and adult skin and in basal cell carcinoma. J Cutan Pathol. 2001; 28: 184-90.

40. Liao CG, Kong LM, Song F, Xing JL, Wang LX, Sun ZJ, Tang H, Yao H, Zhang Y, Wang L, Wang Y, Yang XM, $\mathrm{Li}$ Y, et al. Characterization of basigin isoforms and the inhibitory function of basigin-3 in human hepatocellular carcinoma proliferation and invasion. Mol Cell Biol. 2011; 31: 2591-604. doi: 10.1128/MCB.05160-11.
41. Tang Y, Nakada MT, Kesavan P, McCabe F, Millar H, Rafferty P, Bugelski P, Yan L. Extracellular matrix metalloproteinase inducer stimulates tumor angiogenesis by elevating vascular endothelial cell growth factor and matrix metalloproteinases. Cancer Res. 2005; 65: 3193-9. doi: 10.1158/0008-5472.CAN-04-3605.

42. Jia L, Wang H, Qu S, Miao X, Zhang J. CD147 regulates vascular endothelial growth factor-A expression, tumorigenicity, and chemosensitivity to curcumin in hepatocellular carcinoma. IUBMB Life. 2008; 60: 57-63. doi: 10.1002/iub.11.

43. Yang JM, O’Neill P, Jin W, Foty R, Medina DJ, Xu Z, Lomas M, Arndt GM, Tang Y, Nakada M, Yan L, Hait WN. Extracellular matrix metalloproteinase inducer (CD147) confers resistance of breast cancer cells to Anoikis through inhibition of Bim. J Biol Chem. 2006; 281: 9719-27. doi: 10.1074/jbc.M508421200.

44. Slomiany MG, Grass GD, Robertson AD, Yang XY, Maria BL, Beeson C, Toole BP. Hyaluronan, CD44, and emmprin regulate lactate efflux and membrane localization of monocarboxylate transporters in human breast carcinoma cells. Cancer Res. 2009; 69: 1293-301. doi: 10.1158/00085472.CAN-08-2491.

45. Sidhu SS, Nawroth R, Retz M, Lemjabbar-Alaoui H, Dasari V, Basbaum C. EMMPRIN regulates the canonical Wnt/beta-catenin signaling pathway, a potential role in accelerating lung tumorigenesis. Oncogene. 2010; 29: 414556. doi: 10.1038/onc.2010.166.

46. Wu J, Ru NY, Zhang Y, Li Y, Wei D, Ren Z, Huang XF, Chen ZN, Bian H. HAb18G/CD147 promotes epithelialmesenchymal transition through TGF-beta signaling and is transcriptionally regulated by Slug. Oncogene. 2011; 30: 4410-27. doi: 10.1038/onc.2011.149.

47. Mi Z, Oliver T, Guo H, Gao C, Kuo PC. Thrombincleaved $\mathrm{COOH}(-)$ terminal osteopontin peptide binds with cyclophilin C to CD147 in murine breast cancer cells. Cancer Res. 2007; 67: 4088-97. doi: 10.1158/0008-5472. CAN-06-4066.

48. Seizer P, Klingel K, Sauter M, Westermann D, Ochmann C, Schonberger T, Schleicher R, Stellos K, Schmidt EM, Borst O, Bigalke B, Kandolf R, Langer H, et al. Cyclophilin A affects inflammation, virus elimination and myocardial fibrosis in coxsackievirus B3-induced myocarditis. J Mol Cell Cardiol. 2012; 53: 6-14. doi: 10.1016/j. yjmcc.2012.03.004.

49. Dear JW, Simpson KJ, Nicolai MP, Catterson JH, Street J, Huizinga T, Craig DG, Dhaliwal K, Webb S, Bateman DN, Webb DJ. Cyclophilin A is a damage-associated molecular pattern molecule that mediates acetaminophen-induced liver injury. J Immunol. 2011; 187: 3347-52. doi: 10.4049/ jimmunol.1100165.

50. Pushkarsky T, Zybarth G, Dubrovsky L, Yurchenko V, Tang H, Guo H, Toole B, Sherry B, Bukrinsky M. CD147 facilitates HIV-1 infection by interacting with virus- 
associated cyclophilin A. Proc Natl Acad Sci U S A. 2001; 98: 6360-5. doi: 10.1073/pnas.111583198.

51. Qian Z, Zhao X, Jiang M, Jia W, Zhang C, Wang Y, Li B, Yue W. Downregulation of cyclophilin A by siRNA diminishes non-small cell lung cancer cell growth and metastasis via the regulation of matrix metallopeptidase 9 . BMC Cancer. 2012; 12: 442. doi: 10.1186/1471-2407-12442.

52. Obchoei S, Weakley SM, Wongkham S, Wongkham C, Sawanyawisuth K, Yao Q, Chen C. Cyclophilin A enhances cell proliferation and tumor growth of liver fluke-associated cholangiocarcinoma. Mol Cancer. 2011; 10: 102. doi: 10.1186/1476-4598-10-102.

53. Howard BA, Furumai R, Campa MJ, Rabbani ZN, Vujaskovic Z, Wang XF, Patz EF, Jr. Stable RNA interference-mediated suppression of cyclophilin A diminishes non-small-cell lung tumor growth in vivo. Cancer Res. 2005; 65: 8853-60. doi: 10.1158/0008-5472. CAN-05-1219.

54. Li M, Zhai Q, Bharadwaj U, Wang H, Li F, Fisher WE, Chen C, Yao Q. Cyclophilin A is overexpressed in human pancreatic cancer cells and stimulates cell proliferation through CD147. Cancer. 2006; 106: 2284-94. doi: 10.1002/ cncr.21862.

55. Satoh K, Nigro P, Matoba T, O'Dell MR, Cui Z, Shi X, Mohan A, Yan C, Abe J, Illig KA, Berk BC. Cyclophilin A enhances vascular oxidative stress and the development of angiotensin II-induced aortic aneurysms. Nat Med. 2009; 15: 649-56. doi: 10.1038/nm.1958.

56. Satoh K, Matoba T, Suzuki J, O’Dell MR, Nigro P, Cui Z, Mohan A, Pan S, Li L, Jin ZG, Yan C, Abe J, Berk BC. Cyclophilin A mediates vascular remodeling by promoting inflammation and vascular smooth muscle cell proliferation. Circulation. 2008; 117: 3088-98. doi: 10.1161/CIRCULATIONAHA.107.756106.

57. Yurchenko V, Zybarth G, O'Connor M, Dai WW, Franchin G, Hao T, Guo H, Hung HC, Toole B, Gallay P, Sherry $\mathrm{B}$, Bukrinsky M. Active site residues of cyclophilin A are crucial for its signaling activity via CD147. J Biol Chem. 2002; 277: 22959-65. doi: 10.1074/jbc.M201593200.

58. Konttinen YT, Li TF, Mandelin J, Liljestrom M, Sorsa T, Santavirta S, Virtanen I. Increased expression of extracellular matrix metalloproteinase inducer in rheumatoid synovium. Arthritis Rheum. 2000; 43: 27580. doi: 10.1002/1529-0131(200002)43:2<275::AIDANR6>3.0.CO;2-\#.
59. Hatanaka M, Higashi Y, Kawai K, Su J, Zeng W, Chen X, Kanekura T. CD147-targeted siRNA in A375 malignant melanoma cells induces the phosphorylation of EGFR and downregulates cde25C and MEK phosphorylation. Oncol Lett. 2016; 11: 2424-8. doi: 10.3892/ol.2016.4267.

60. Baba $\mathrm{M}$, Inoue $\mathrm{M}$, Itoh $\mathrm{K}$, Nishizawa $\mathrm{Y}$. Blocking CD147 induces cell death in cancer cells through impairment of glycolytic energy metabolism. Biochem Biophys Res Commun. 2008; 374: 111-6. doi: 10.1016/j. bbrc.2008.06.122.

61. Claesson-Welsh L, Welsh M. VEGFA and tumour angiogenesis. J Intern Med. 2013; 273: 114-27. doi: 10.1111/joim.12019.

62. Huang C, Sun Z, Sun Y, Chen X, Zhu X, Fan C, Liu B, Zhao $\mathrm{Y}$, Zhang W. Association of increased ligand cyclophilin A and receptor CD147 with hypoxia, angiogenesis, metastasis and prognosis of tongue squamous cell carcinoma. Histopathology. 2012; 60: 793-803. doi: 10.1111/j.13652559.2011.04130.x.

63. Chen Y, Gou X, Ke X, Cui H, Chen Z. Human tumor cells induce angiogenesis through positive feedback between CD147 and insulin-like growth factor-I. PLoS One. 2012; 7: e40965. doi: 10.1371/journal. pone.0040965PONE-D-11-21993.

64. Wang CH, Yao H, Chen LN, Jia JF, Wang L, Dai JY, Zheng ZH, Chen ZN, Zhu P. CD147 induces angiogenesis through a vascular endothelial growth factor and hypoxia-inducible transcription factor 1alpha-mediated pathway in rheumatoid arthritis. Arthritis Rheum. 2012; 64: 1818-27. doi: 10.1002/ art.34341.

65. Voigt H, Vetter-Kauczok CS, Schrama D, Hofmann UB, Becker JC, Houben R. CD147 impacts angiogenesis and metastasis formation. Cancer Invest. 2009; 27: 329-33. doi: 10.1080/07357900802392675.

66. Fu J, Chen X, Zhang Y, Gu H, Bai Y. CD147 and VEGF co-expression predicts prognosis in patients with acute myeloid leukemia. Jpn J Clin Oncol. 2010; 40: 1046-52. doi: 10.1093/jjco/hyq098hyq098.

67. Dear JW, Leelahavanichkul A, Aponte A, Hu X, Constant SL, Hewitt SM, Yuen PS, Star RA. Liver proteomics for therapeutic drug discovery: inhibition of the cyclophilin receptor CD147 attenuates sepsis-induced acute renal failure. Crit Care Med. 2007; 35: 2319-28. 